\title{
Public perception of bioenergy in North Carolina and Tennessee
}

\author{
Robert I. Radics', Sudipta Dasmohapatra and Stephen S. Kelley
}

\begin{abstract}
Background: The goal of the study is to examine the general public's understanding and perceptions of bioenergy and biofuels in North Carolina (NC) and Tennessee (TN). The study focuses on the public concerns, support and risk evaluations of alternative bioenergy feedstocks and biofuels, and includes an assessment of the economic, environmental, social, and policy impacts of bioenergy production and use.

Methods: A sample of consumers in NC and TN were surveyed in the fall of 2013 and spring of 2014 for their perceptions about bioenergy and specifically, biofuels for transportation. Five hundred eighty-six consumers completed the questionnaire electronically (376 in NC and 210 in TN).

Results: Respondents reported that the price and vehicle compatibility with biomass-based transportation fuels were the most important factors in their choice of biofuels over gasoline at a pump. Results show that the acceptance of bioenergy depends on the extent of knowledge and available information to consumers about the energy source. A principal component analysis (PCA) indicated seven distinct dimensions of consumer's perception about bioenergy. The key dimensions are the following: how bioenergy benefits the society, risks of bioenergy use, government support for bioenergy, increase in food cost, conditional use of trees, support for low-cost biofuel alternative to current energy, and market attributes of bioenergy purchase.

Conclusions: The findings from this study reflect the need for communicating the benefits and risks from the use of bioenergy to the general public through trustworthy channels of communication and targeted policy, market, and institutional support.
\end{abstract}

Keywords: Bioenergy, Biofuels, General public, Perception

\section{Background}

The 2007 Energy Independence and Security Act (EISA) mandates the production and use of 36 billion gallons of bioethanol using renewable feedstocks by 2022 . Of this, 21 billion gallons are required to be produced from noncorn feedstock. The U.S. Department of Energy has also highlighted the potential for production of other types of bioproducts (e.g., chemicals) for a greener, low-carbon society [1]. The successful diffusion of technologies and acceptance of any new product such as bioethanol/diesel or other bioproducts is not solely dependent on its technical and economic advantages; societal acceptance plays an important role and sometimes even

\footnotetext{
*Correspondence: riradics@ncsu.edu

Department of Forest Biomaterials, North Carolina State University, Campus Box 8005, Raleigh, NC 27695, USA
}

serves as the key indicator for a bioenergy product's success in the marketplace [2].

A standard method for assessing societal acceptance is through measurement of stakeholders' perception of product performance and their opinion on risks and opportunities in the product's use [3]. In the last decade, many publications have focused on stakeholder perceptions of bioenergy and biofuels for transportation by studying the attitudes and sometimes the behavior of the stakeholders [4-16]. Although a high percentage of these studies have an international focus, they still provide extremely useful information about bioenergy acceptance and stakeholder concerns, as this industry gains momentum across the globe. Nevertheless, we postulate that the production of the biomass and fuels are local activities, and hence, the most noticeable direct impacts are likely to occur in the region surrounding a biorefinery. 
Past literature points out that the local impact of corn ethanol plants includes perceived benefits such as creation of local employment and money flowing into the community whereas, perceived risks include issues such as noticeable odor and increase in air and water emissions [17]. Thus, the risks and opportunities of the bioenergy-related activities need to be assessed from the local or regional stakeholder's point of view.

The Southeast US belt is considered to have the potential for producing almost $50 \%$ of the next generation of biomass and biofuels according to the U.S. Department of Energy [1]. More than $45 \%$ of cellulosic feedstocks and $70 \%$ of the forest biomass is produced in the Southeast US [18]. The opportunities for biomass production in the Southeast US are driven by the relatively long growing season and abundance of rainfall, private land ownership patterns that allow shorter transportation distances, and a strong history of community and industrial support for farming and commercial forestry.

This study aims to understand the perceptions of the general public about bioenergy and specifically, biofuels, in the state of North Carolina and Tennessee. These two states among themselves represent the SE US when considering the type of weather conditions as well as the biomass diversity and availability for the bioenergy industry.

Most past studies on general public perceptions are focused either outside of the US, or when domestic (US) have either a very broad resource focus (green electricity or renewable electricity instead of biofuels or biomassbased energy) or a particular community focus around an existing or potential bioenergy pilot plant. In addition, many studies about general public are specifically student at a high school or university which cannot be translated to mean the same as the perceptions of the adult general public [19]. Thus, the results of these studies provide highly dispersed results, indicating the need for a systematic study that provides a better basis for strategies to clarify the public acceptance, primarily addressing the Southeast US. The next section provides a brief synthesis of the results from past studies on consumer perceptions of bioenergy.

\section{Synthesis of past studies on the general public's (adults) perception of bioenergy and biofuels for transportation General support of bioenergy}

Studies focused on the attitudes of the general public indicate a moderate (and sometimes low) to ambivalent support towards renewable energy including biomassbased energy [18, 20-25]. Most studies attribute the low acceptance and support for bio-based energy to the lack of awareness and knowledge about this industry among the general public $[5,16,21,23,25,26]$.

\section{Economy and the environment}

A brief analysis of the studies shows that consumers support or oppose bioenergy based on their consideration primarily on the four attributes of bioenergy (environment, social, economic, and market) when compared to alternative scenarios. Citizens in some studies indicate that they would support bioenergy if it had a positive environmental impact compared to fossil fuels [13, 27, 28]. In fact, the perceived environmental attributes of biofuels are found to be a major factor in consumers' choice of biomassbased fuels at gas stations in some studies [21, 26]. Other studies found positive perception about renewable energy including biomass-based energy to depend on social benefits such as jobs for the community [12, 17, 24] and its ability to provide national security in terms of transportation fuels $[13,22]$. The public indicates that risks such as increase in pollution including noise, traffic, air $[6,17]$, and threat to land availability for food production and increased food price are the negative attributes of bioenergy growth [10,29].

\section{Feedstock awareness}

Some studies on consumer perceptions of renewable energy or bioenergy compared various biomass-based energy sources with that of other renewable sources. Nearly all studies found that citizens are more willing to support and accept solar, wind, and hydro energy sources relative to biomass-based energy $[18,20,21,26,30]$. This is in large part, due to the relatively recent introduction of bioenergy compared to these other energy sources in the marketplace and the associated lack of knowledge of biomass-based energy impacts on the society.

The type of feedstock used for producing biomass-based energy (particularly, fuels) is also reported to have an impact on public support. Studies have found higher levels of public support for energy produced from landfill wastes, wood waste, and grasses and corn stover, while trees, genetically modified organisms (GMOs), and cornbased bioethanol have lower levels of support [21, 26].

\section{Choosing biofuels}

When asked about biomass-based fuels vs. gasoline choice at gas stations, convenience and availability of biofuels at most filling stations and price of biofuels vs. gasoline are reported as important to consumers governing their choice of biofuels $[4,6,7,21,25,26,30-34]$.

\section{Methods}

The goal of the study is to examine the general public's understanding and perceptions of bioenergy and biofuels in North Carolina (NC) and Tennessee (TN). Specifically, this study focuses on the public concerns, support, and risk evaluations of alternative bioenergy feedstocks and biofuels (for transportation), and includes an assessment 
of the economic, environmental, social, and policy impacts of bioenergy production and use. The results provide directions for policy decisions and educational outcomes specific to the general public. The research proposal was approved by the North Carolina State University Institutional Review Board at March 14, 2013 (IRB 3161; Assurance number FWA00003429).

An electronic survey instrument was used to collect data from the general public in NC and TN. The survey was designed using Qualtrics, an online survey software and insight platform. The survey questions were constructed based on past studies on consumer's perception of bioenergy (studies mentioned in the "Background" section) and vetted with project partners and experts (academia, extension, US Forest Service, industry). Prior to the data collection, a pilot study was conducted to test the effectiveness of the survey questions, check the logic, flow and question wording, and the survey length. A sample $(n=34)$ of consumers responded to the pilot survey before the initiation of the survey. Feedback from the pilot test was used to refine the survey instrument. The final version of the questionnaire contained five categories of questions, including demographics, concerns regarding various environmental topics, understanding of energy sources, bioenergy feedstock preference, and bioenergy-relevant self-constructed 38-item agreement question on four key aspects of bioenergy (economic, environment, social, and policy). In case of concerns and relative agreement type questions, five-element Likert scale was applied ( $1=$ strongly disagree and $5=$ strongly agree).

Approximately, two million email addresses for consumers in NC and TN were obtained from a third party marketing agency in $\mathrm{NC}$ for the data collection. An automatic email sender software was used for the survey distribution. Emails were randomly chosen to be sent in batches of 10,000 per batch to consumers in TN and NC in the fall of 2013 and early spring of 2014 (approximately 100,000 emails were sent). Almost half of the email addresses were not valid (bounce-backs), and no specific data could be obtained from the number of emails received by the consumers, thus making the exact response rate calculation difficult. The email contained a cover letter with a link to the survey. The cover letter included a valid letterhead and information about the importance of the study as well as incentive information for completing the survey (entry into the raffle of $\$ 25.00$ Home Depot gift cards). Three weeks after the first email contact, consumers were sent a reminder to complete the survey, and 3 weeks after the first reminder, they were sent a second reminder email to complete the survey following a modified version of Dillman et al.'s Tailored Design Method [35].
Sample and population differences were shown in Table 1 and discussed in the results part. Data collected from the responses was adjusted (weighted) to reflect the demographics of NC and TN based on the 2013 state census. This weighting method (a procedure called raking) is designed to improve the relationship between the sample and the population by fine-tuning the sampling weights of the cases when more than one weighting parameter or variable is used [36]. The raking procedure has been effectively used in data with small samples (as in this study) providing very precise and unbiased estimates [37]. The raking weighting method is similar to iterative proportional fitting that adjusts a set of data in a stepwise process so that its marginal totals match the specified control totals on a specific set of variables [36]. Variables included in the raking procedure for weighting in this study included age, gender, education, and income of respondents.

Principal component analysis (PCA) was used to reduce the number of dimensions from scale-level agreement questions by finding statistically correlated variables. The reduction in the number of variables is obtained by transforming the original variables to a new smaller set of variables, called principal components, which were uncorrelated [38]. PCA will be used in this paper to model the broad dimensions of bioenergy perceived by the general public when making decisions about the benefits and risks of bioenergy.

Table 1 Comparison of sample demographic and census data

\begin{tabular}{lllll}
\hline Demographics & NC (\%) & $\begin{array}{l}\text { NC 2013 } \\
\text { census (\%) }\end{array}$ & $\begin{array}{l}\text { TN (\%) } \\
n=377\end{array}$ & $\begin{array}{l}\text { TN 2013 } \\
\text { census (\%) }\end{array}$ \\
\hline Gender & 54 & 49 & 46 & 49 \\
$\quad$ Male & 46 & 51 & 54 & 51 \\
$\quad$ Female & & & & \\
Education & 42 & 65 & 43 & 70 \\
High School and less & 29 & 9 & 31 & 6 \\
Some college/associates & 2900 \\
Bachelor's degree & 18 & 18 & 18 & 15 \\
Graduate or professional & 11 & 9 & 9 & 8 \\
Ethnicity & & & & \\
White/Caucasian & 79 & 72 & 89 & 79 \\
Black/African-American & 10 & 22 & 7 & 17 \\
Age (years) & & & & \\
18-24 & 2 & 14 & 13 & 13. \\
25-44 & 27 & 36 & 55 & 35 \\
$45-64$ & 53 & 35 & 31 & 35 \\
$65+$ & 18 & 16 & 1 & 17 \\
\hline
\end{tabular}




\section{Results}

\section{Response and demographics}

We received 586 completed questionnaires with 377 responses from NC and 209 responses from TN. Making the exact response rate calculation was difficult due to the quality of the third party provided email address database-almost half of the email addresses were not valid (bounce-backs), and no specific data could be obtained from the number of emails received by the consumers. Also, the length of the questionnaire (100 questions) was restraining. Before the weighting adjustment described above, non-response bias was measured between early and late responses based on demographic and biofuel agreement statement variables using the independent samples $t$ test (continuous variables) and the chi-square test (nominal variables). A non-response bias analysis examines whether respondents of the study were different from non-respondents. Past research has shown that non-respondents behave similar to the late respondents or respondents that respond after a reminder [35]. Early respondents in this study were defined as those who responded before any reminder was sent, and late respondents were defined as all those who answered after the reminder was emailed. The $t$ test and the chi-square test did not reveal significant difference between the two respondent groups (early, $n=405$ vs. late, $n=181$ ) on any variable.

In general, the respondents were more educated, mostly were White/Caucasian, and older compared to 2013 census data, especially in NC (Table 1). Thus, the responses were weighted so that the results were more representative of the state's population. The changes caused by raking to reflect the demographics of NC and TN were the largest where the sample and the population demographics differed the greatest, e.g., the $\mathrm{NC}$ population adjusted for education and the TN age $(65+)$. To reduce the larger weights, the variables such as age and education were binned to a smaller number of categories (instead of seven age categories, we used only four age groups for age as shown in Table 1). The mode for the weight was found to be 1.12 and extremely large weights $(\sim 10)$ occurred only in $15 \%$ of the overall sample (minimum weight was 0.12 .)

\section{Level of concern about economy and the environment}

Respondents were asked to indicate their level of concern about the selected economic and environmental topics that impact bioenergy. The price of energy, unemployment, and US dependence on foreign oil were reported by the general public as most concerning (Fig. 1). Among the selected topics, the respondents were least worried about greenhouse gas emissions and decreasing fossil reserves. The results showed relatively higher variation (standard deviation of 1.5 and above) in consumer concerns for food price, global climate change, and greenhouse gas emissions.

\section{Source of energy reported renewable}

Respondents were asked to indicate whether different energy sources were renewable or non-renewable. The respondents had the option to indicate "not sure" or "never heard," wherever appropriate. Approximately, 17 and $20 \%$ of respondents, respectively, reported that coal and petroleum were renewable. Geothermal, tidal, trees, and grasses were ranked as the least recognized energy sources. Similar to past studies $[18,21,26,30]$, our results showed that more respondents recognized solar and wind energy as renewable than other energy

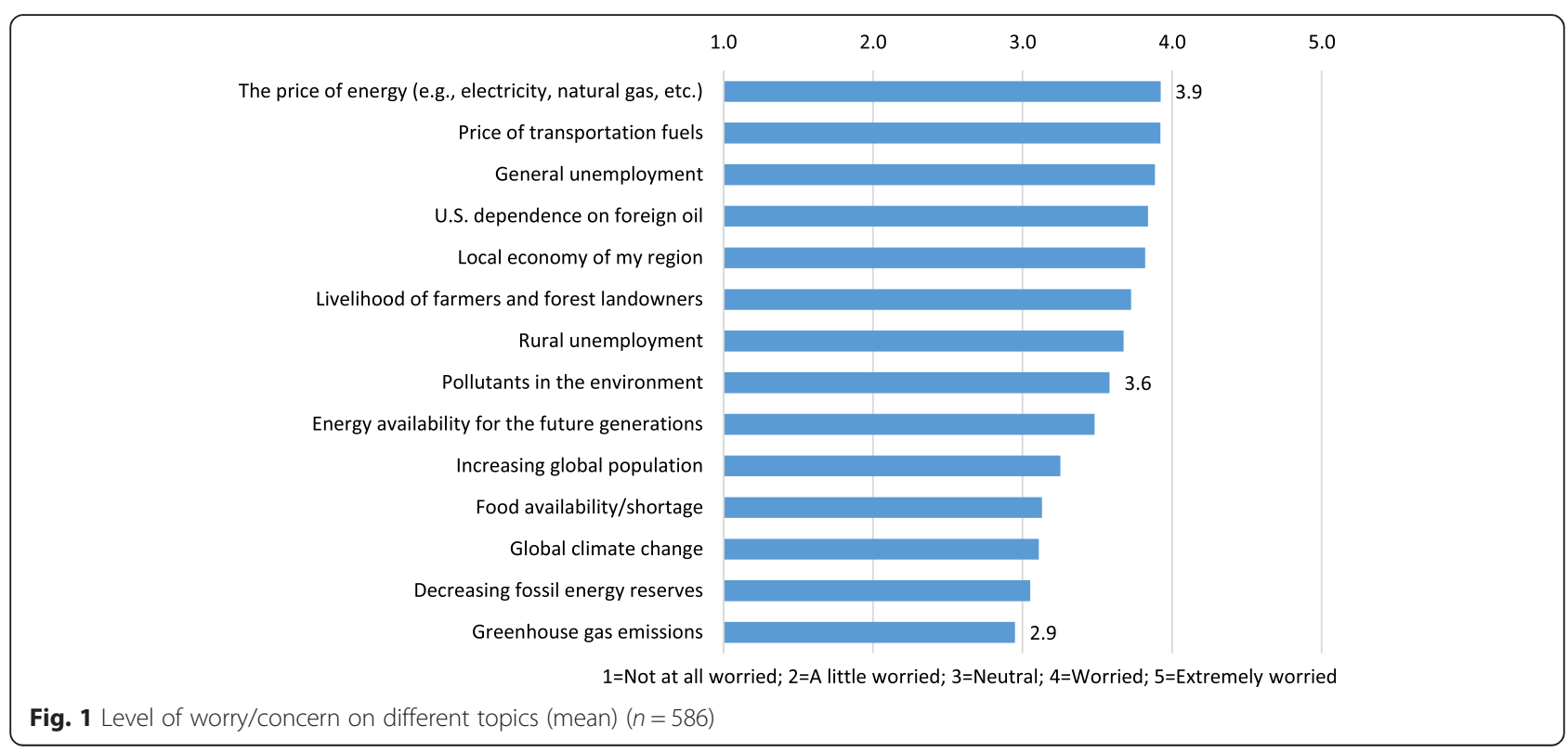


sources, especially when compared to biomass-based energy sources (Fig. 2).

Among the above listed sources of energy, over $40 \%$ of respondents either had not heard about tidal energy or were unsure if tidal source was renewable. Over $35 \%$ of sample also reported that they had never heard about trees as source of energy or were unsure that trees were renewable.

\section{Feedstock awareness}

Respondents were asked to indicate their willingness to purchase transportation fuels based on various biomass sources for fuels. The willingness to buy survey question was used to represent respondent approval for the application of feedstock in transportation fuels, similar to other studies [21, 26, 30]. Figure 3 shows the most accepted biofuel sources (highest willingness to purchase percentage among respondents) as crop residues, corn, agricultural crops, and grasses followed by forest residues/trees. The least preferred (lowest willing to purchase percentage) sources for purchase were reported as genetically modified trees and crops, which is found to be consistent with earlier studies [21, 26]. Among feedstock sources for energy, genetically modified trees and algae/duckweed were reported most frequently as unheard sources, followed by landfill wastes, forest and wood products residues or trees, grasses, and genetically modified crops (Fig. 4).

\section{Importance of factors in the choice of biofuels for transportation}

When asked to indicate what factors motivate the purchase of biomass-based fuels at gas pump, respondents indicate price, vehicle compatibility with fuels, and performance of vehicles as the most important factors (Fig. 5). The opinion of friends and family was reported to have the least influence on the respondents' choice of biofuels at the pump.

\section{Principal component analysis}

PCA of the relative agreement statements of bioenergy showed seven key principal components (PC) or dimensions that explain $71.2 \%$ of the variation in the responses for the bioenergy statements. These seven dimensions show broad categories or the unobserved concepts of bioenergy that consumers think about when making decisions about bioenergy use, consumption, benefits, and risks. These unobserved concepts of consumer attitudes towards bioenergy/biofuels are based on the linear combination of 24 bioenergy statement variables that fit well in the PCA model (Table 2). Variables that showed a low loading (less than 0.50) on any of the principal components were unacceptable (did not fit) with the model. Table 2 shows principal components with the corresponding variables that are explained highly by the principal components, the loading values for each of the variables, and the mean values of the variables. The variables that have high loading values for a principal component are grouped under that principal component. The higher the value of the loadings, the more the variation in the variable explained by the principal component. The corresponding alpha level for each principal component reflects how consistently the variables measure the principal component. Values at and above 0.50 for alpha are acceptable [39]. The first principal component dimension "bioenergy benefits to society"

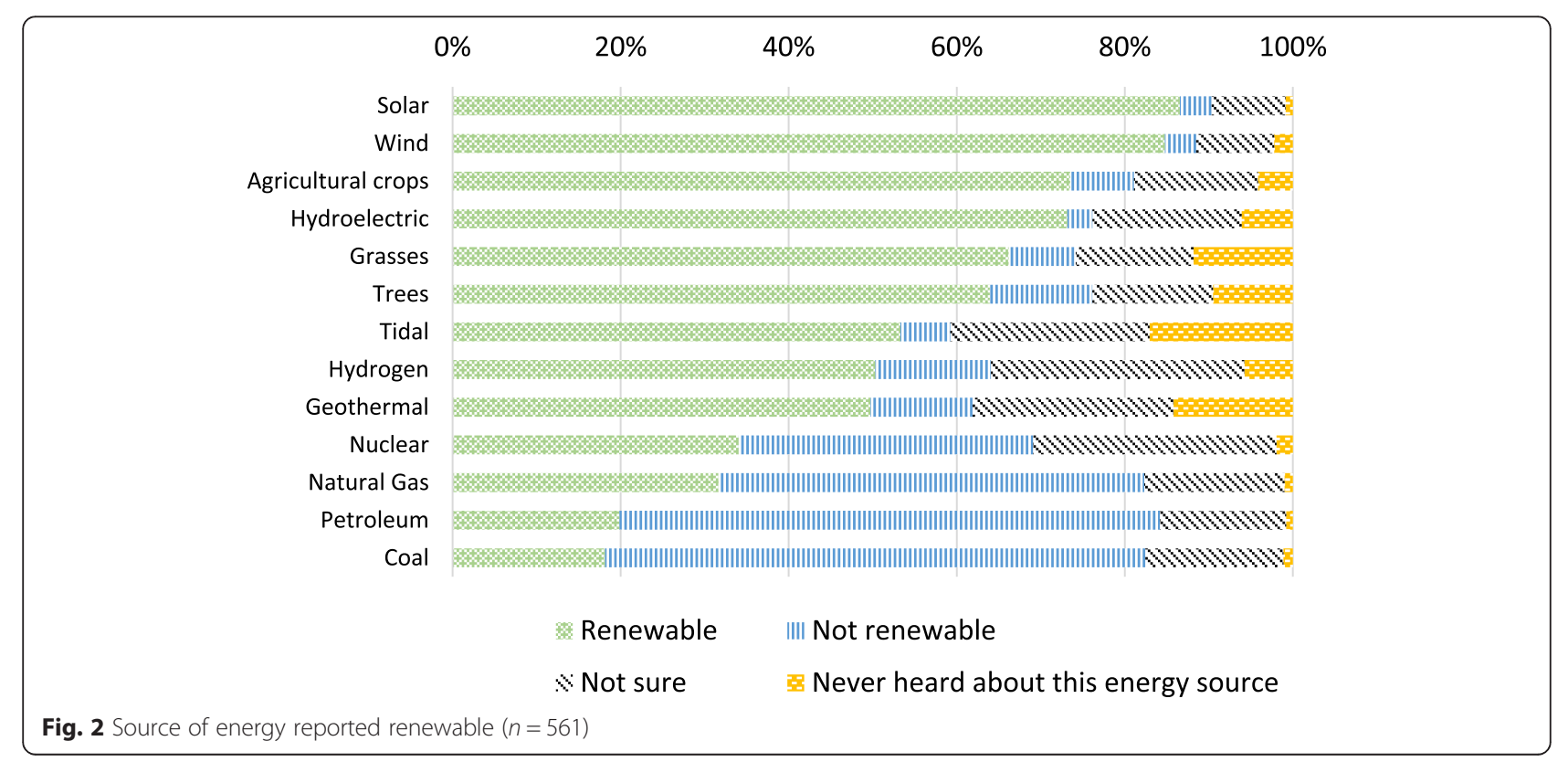


$\begin{array}{lllllllllll}0 \% & 10 \% & 20 \% & 30 \% & 40 \% & 50 \% & 60 \% & 70 \% & 80 \% & 90 \% & 100 \%\end{array}$

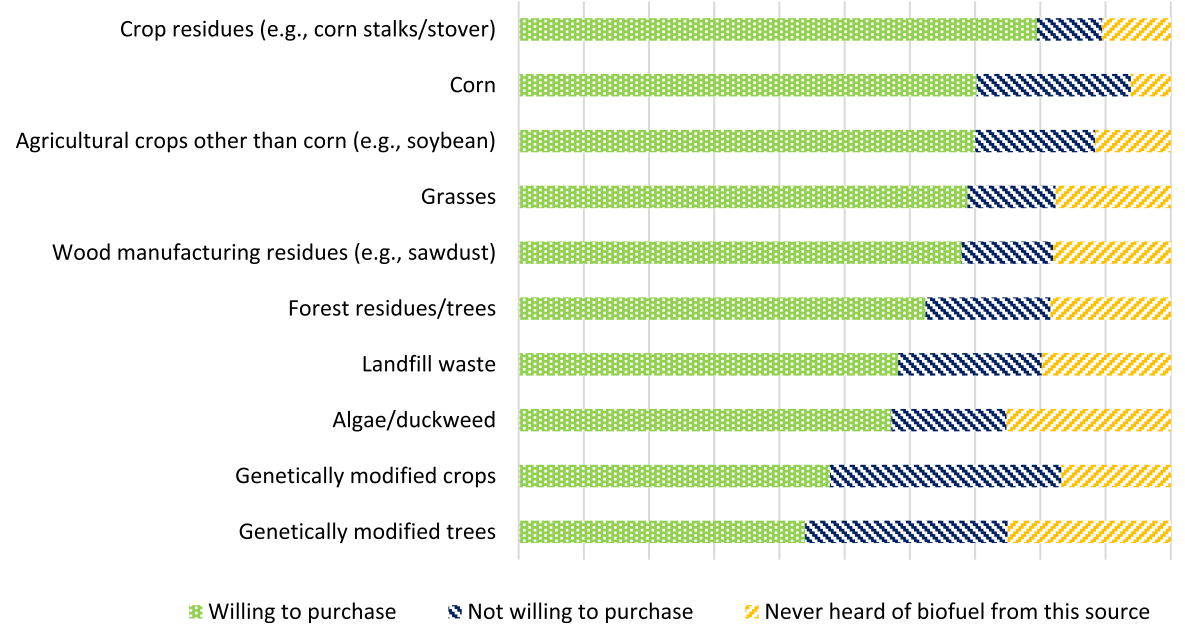

Fig. 3 Willingness to purchase biofuels (for transportation) from different biomass feedstocks $(n=558)$

has an alpha of 0.89 among the variables. This means that the variables/statements for national security, improvement in jobs and rural economy, and higher benefits than risk of bioenergy use explain that dimension well. The variation in each of the three variables is explained well by the bioenergy benefits to society component. The second dimension of bioenergy represents variables that show the "risks of bioenergy use" (alpha = 0.78). The dimension consists of statements that reflect bioenergy use leading to negative environmental impact, reduction in vehicle performance, and increase in costs. The third dimension "government support for bioenergy" includes three items (alpha $=0.80$ ) that measure government support required for research and production of bioenergy as well as a source of information. The next dimension shows the competition of fuel vs. food in the society. This dimension measures "increase in food cost" due to biofuel production (alpha $=0.87$ ). The fifth dimension shows some imperative reasoning behind acceptance of trees as feedstock sources. This dimension is labeled "conditional use of trees as feedstocks" (alpha $=0.69$ ). The other dimensions are "support low-cost biofuel alternative to current energy" and "market attribute-based purchase".

\section{Other consumer comments or concerns}

The end of the questionnaire included a free-form question about respondent comments and concerns about bioenergy or biofuels for transportation. One hundred eighty-seven respondents provided comments. After

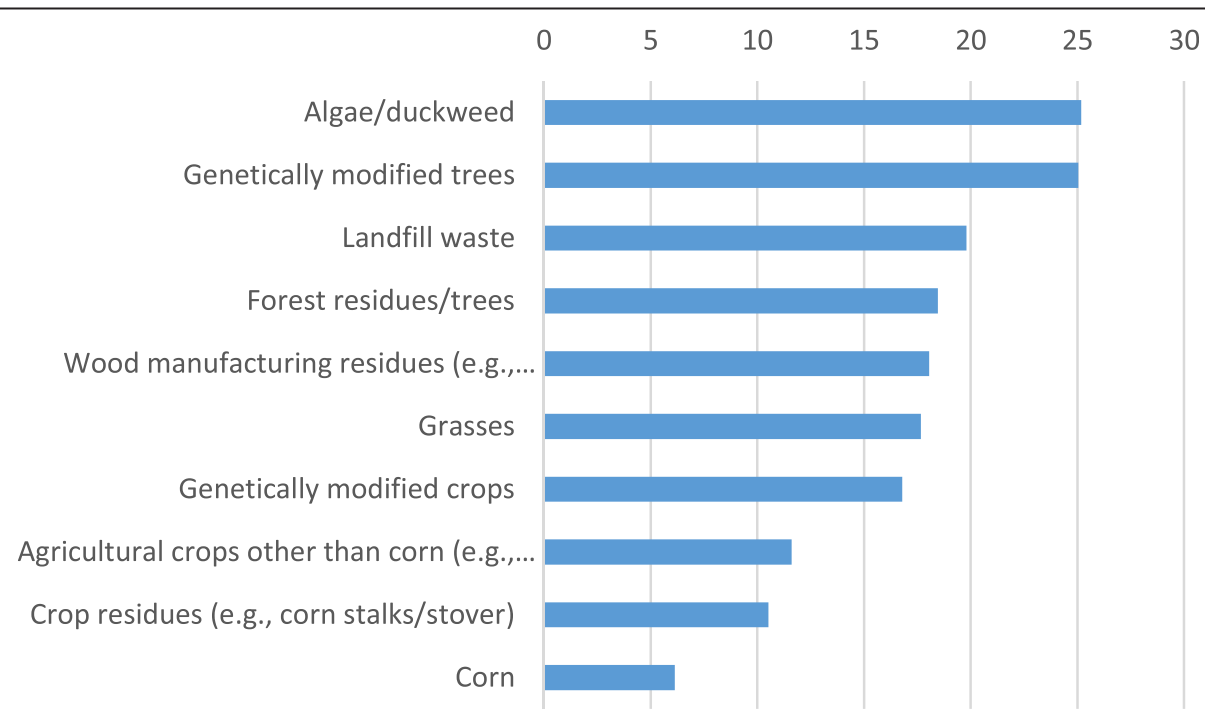

Fig. 4 Percent of consumers who were unaware of energy sources $(n=558)$ 
1=Extremely Unimportant; 2=Unimportant; 3=Neutral; 4=Important; 5=Extremely Important

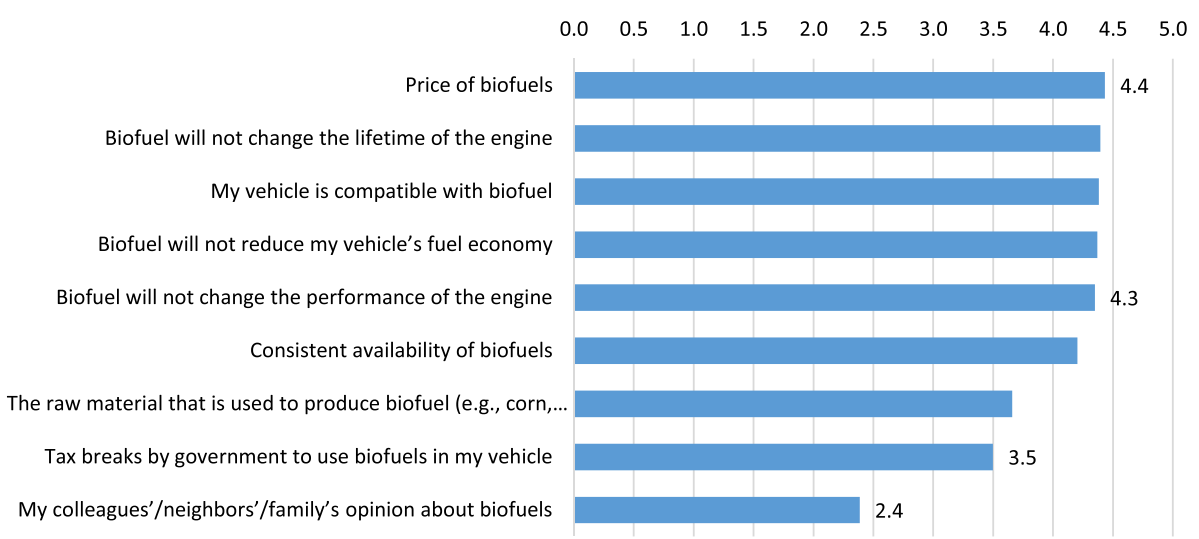

Fig. 5 Importance of factors in the choice of biofuels for transportation (mean) $(n=542)$

categorizing these responses into groups, we found almost half of responses were about on negative impacts or risks from bioenergy. These issues include higher costs of production, competing land area for food and fuel, over-reliance on tax subsidies for fuel production and distribution, and environmental risks of bioenergy related to unintended environmental impacts such as air pollution or water pollution. Almost $30 \%$ of responses reflected concerns about biofuel (for transportation) negatively affecting vehicle performance (including responses that included support for bioenergy only if they had no negative impact on the vehicles' engines.) Approximately, $20 \%$ of comments were about the benefits and opportunities in support for bioenergy industry (respondents indicated that they would support bioenergy if subsidies were available and if there was a free and open market where biofuels competed with gasoline and other energy products. Approximately, $5 \%$ of openended comments reported support to bioenergy because it would reduce dependence on foreign oil and increase national security, which were found to be major drivers of public support in the past studies [18, 21]. Approximately, a quarter of comments included interest in getting more information about bioenergy economics, use, effect on vehicle performance, and bioenergy environmental impacts.

Respondents indicated that they did not trust the government to provide credible information about bioenergy. They trusted in their local utility companies as well as the extension agents and foresters to provide information on bioenergy and biofuels.

\section{Sources of bioenergy information}

Most of the respondents reported using more than one information source where they have heard or received any information on bioenergy (Fig. 6). Approximately, $56.1 \%$ of sources of information for respondents was sourced from radio and television. Magazines and newspaper were the second most important channels (42.8\%) for bioenergy information followed by utility companies $(25.5 \%$ of all sources). Governmental websites were the least commonly used sources of information on bioenergy.

\section{Discussion}

The data from our study shows that the general public varies widely in their awareness and knowledge about biomass-based energy and biofuels (for transportation).

Most consumers are worried about the price of energy over the price of fuels, unemployment, national security, and critical environment issues. Other past studies have also identified these same concerns, although the ranking of these issues varies [3, 40-43]. These differences could be attributed to the changing economy, business climate, political conditions, and region of the country.

Respondents recognize solar and wind energy sources primarily as renewable energy sources, compared to all others including biomass-based energy. This finding is consistent with other past studies [10, 21, 26, 30]. Also, the focus on bioenergy is quite recent whereas other sources including tidal, wind, and solar technology have received considerable attention in large-scale commercial projects for at least a couple of decades. Among biomass sources for energy, landfill waste, agricultural crops, and trees are positively perceived by the public. The forest and bioenergy industry should, however, consider that people report supporting trees as feedstocks only if new trees are planted to replace the harvested trees. In earlier studies, corn-based ethanol was found to be a less preferred feedstock $[21,26]$ whereas respondents in our study ranked corn-based biofuel (for transportation) second in their preference for purchase. 
Table 2 Key unobserved dimensions of consumers' bioenergy perception $(n=586)$

\begin{tabular}{|c|c|c|c|}
\hline Key dimensions and items $(n=508)$ & Mean ratings (1 to 5 ) & Loadings on dimensions & Variation explained (\%) \\
\hline Bioenergy benefits to society (PC1) & & Alpha $=0.89$ & 28.52 \\
\hline I believe that investment in the biofuel industry will create jobs & 3.82 & 0.81 & \\
\hline Using biofuels will reduce US dependence on foreign oil & 3.80 & 0.77 & \\
\hline We should produce biofuels to meet our country's energy demand & 3.65 & 0.76 & \\
\hline I think the biofuel industry will improve the rural economy & 3.49 & 0.75 & \\
\hline $\begin{array}{l}\text { I believe biofuel refineries in my region could provide better } \\
\text { employment opportunities }\end{array}$ & 3.80 & 0.73 & \\
\hline $\begin{array}{l}\text { I believe the biofuel industry will have more benefits than risks } \\
\text { for the society }\end{array}$ & 3.60 & 0.66 & \\
\hline Risks of bioenergy use (PC2) & & Alpha $=0.78$ & 16.94 \\
\hline I believe a biofuel facility in my local area will cause pollution issues & 3.01 & 0.73 & \\
\hline $\begin{array}{l}\text { Biofuels are not environmentally friendly (they take more energy } \\
\text { to make than it is worth) }\end{array}$ & 2.83 & 0.71 & \\
\hline $\begin{array}{l}\text { I am concerned that using biofuels will lower my vehicle's gas } \\
\text { mileage }\end{array}$ & 3.33 & 0.66 & \\
\hline $\begin{array}{l}\text { I believe our taxes will rise if we produce and use biofuels at a } \\
\text { large scale }\end{array}$ & 3.14 & 0.62 & \\
\hline $\begin{array}{l}\text { I would not purchase biofuels because they might be bad for } \\
\text { my car engine }\end{array}$ & 3.16 & 0.62 & \\
\hline Government support for bioenergy (PC3) & & Alpha $=0.80$ & 7.03 \\
\hline $\begin{array}{l}\text { I trust the government to give me credible information about } \\
\text { biofuels }\end{array}$ & 2.56 & 0.81 & \\
\hline $\begin{array}{l}\text { I think the government should subsidize the manufacturing } \\
\text { of biofuels }\end{array}$ & 2.96 & 0.74 & \\
\hline $\begin{array}{l}\text { I think the government should invest more in bioenergy } \\
\text { research } \\
\text { and production }\end{array}$ & 3.32 & 0.64 & \\
\hline Increase in food cost (PC4) & & Alpha $=0.87$ & 5.75 \\
\hline I think biofuels will cause food to be more expensive & 3.42 & 0.84 & \\
\hline $\begin{array}{l}\text { I think biofuels made from corn will cause food to be more } \\
\text { expensive }\end{array}$ & 3.55 & 0.81 & \\
\hline Conditional use of trees as feedstocks (PC5) & & Alpha $=0.69$ & 4.78 \\
\hline $\begin{array}{l}\text { I would support the cutting of trees for biofuels if it significantly } \\
\text { reduces oil imports into the US }\end{array}$ & 3.07 & 0.84 & \\
\hline $\begin{array}{l}\text { I would support the cutting of trees for biofuels if for each tree } \\
\text { cut another was replanted }\end{array}$ & 3.64 & 0.77 & \\
\hline Support low cost biofuel alternative to current energy (PC6) & & Alpha $=0.50$ & 4.20 \\
\hline $\begin{array}{l}\text { I would only choose biofuels if they are lower in price than } \\
\text { gasoline }\end{array}$ & 3.42 & 0.77 & \\
\hline $\begin{array}{l}\text { I would purchase biofuels even if it is a little more expensive } \\
\text { than gasoline }\end{array}$ & 2.70 & -0.66 & \\
\hline $\begin{array}{l}\text { I would not like my local power provider to use renewable } \\
\text { fuels sources if it costs me more money }\end{array}$ & 3.51 & 0.58 & \\
\hline Market attribute-based purchase (PC7) & & Alpha $=0.58$ & 4.00 \\
\hline I would only purchase biofuels if they were the same price as gasoline & 3.33 & 0.80 & \\
\hline $\begin{array}{l}\text { I would only purchase biofuels if they were available at most or } \\
\text { all gas stations }\end{array}$ & 3.48 & 0.66 & \\
\hline I would purchase biofuel if it improves the power of my vehicle's engine & 3.67 & 0.63 & \\
\hline
\end{tabular}




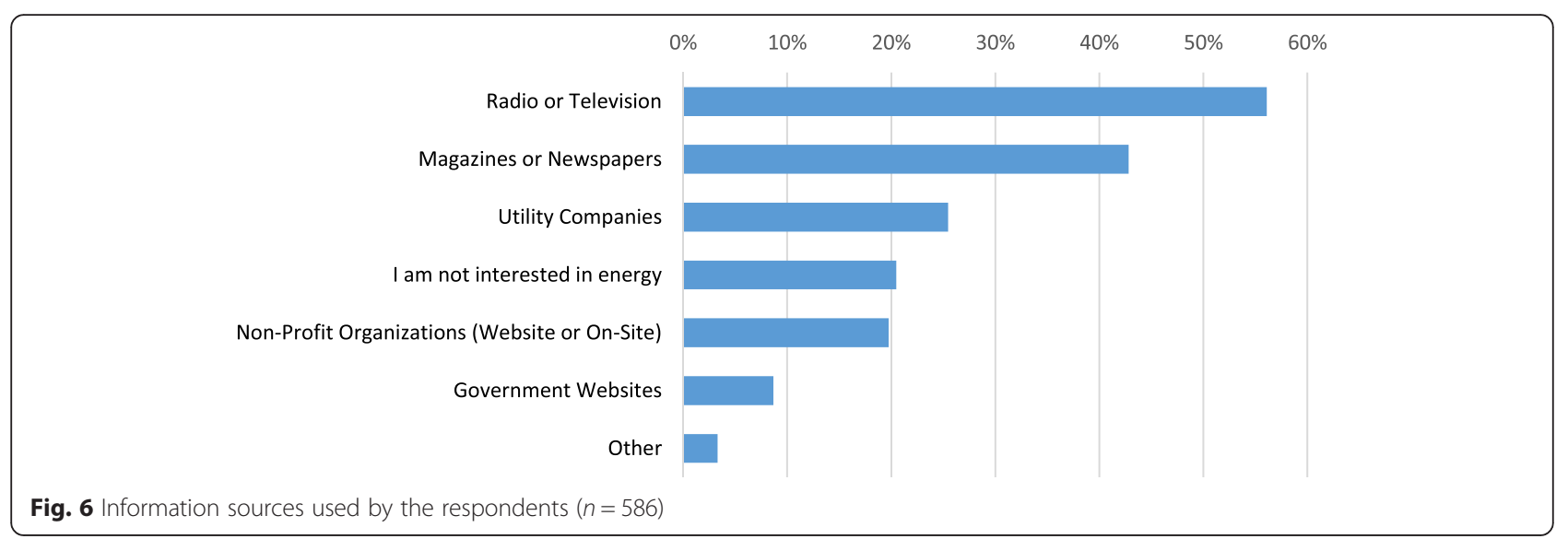

The results of our study show that the general public seeks more information and understanding about bioenergy and biofuels. Specifically, they would like to know more about biofuels' compatibility with their vehicle. We recommend that effective educational tools and information dissemination vehicles be used by the industry that focus on not only bioenergy utilization and impacts but also on its performance effects.

The PCA showed that when consumers make decisions about bioenergy, they think about trade-offs among the seven identified dimensions (how bioenergy benefits the society, risks of bioenergy use, government support for bioenergy, increase in food cost, conditional use of trees, support for low-cost biofuel alternative to current energy, and market attributes of bioenergy purchase).

The findings from our study are somewhat different compared to similar studies in Europe, particularly with respect to biofuels for transportation. We found that the respondents in SE US are concerned about biofuel compatibility with their vehicles, whereas studies in Europe show that about $80 \%$ of consumers are willing to use biofuels in their cars and $45 \%$ are also willing to pay a little premium over the current fuel cost for the use of biofuels [10]. This difference could be attributed to the government mandates and inclusion of bio-based energy and green materials for energy and other uses in Europe.

\section{Conclusions}

There is no doubt that there is a significant lack of information about bioenergy as well as biofuels especially when communicated to the general public [10]. However, because of the way in which the word "bioenergy" is used in the media as well as in research, the public is bound to have difficulty in understanding this concept. In discussions, bioenergy is related to efficient resource use, climate change, carbon footprint, decrease in forest cover, sustainable development, food vs. fuel debate, and among others, making it increasingly confusing for consumers to comprehend [44]. The national ad campaigns, the traditional press, the local and national farm groups, and the National Association for Stock Car Auto Racing (NASCAR) all provide somewhat different views of biofuels for transportation. Thus, if the industry and government machinery would like the bioenergy technologies to be accepted in the marketplace, they need to have a consistent and simpler message delivered through appropriate media channels to the end users/ public. In addition, it is not only the channels and the message that is important but also the interest about bioenergy from consumers may also be affected by how the informational materials are presented [4].

It will also be useful if a deeper understanding is developed about any groups or segments of the population that have varied opinion about bioenergy and to target these segments using appropriate messages and media content $[11,14,23]$. Channels for dissemination of information should be larger than those that garner public trust. Some findings from this study show that people are concerned about the government being a credible source of information. This negative connotation with the word "government" is not new [23]. Local sources (extension agents, foresters) as well as local utility companies, environmental groups are considered more trustworthy compared to government and should be used for information dissemination as much as possible. In addition, collaboration with environmental organizations and academia for outreach is also a key to successful outreach to the general public. It is also important that information providers move away from rather a formalized way of framing the concept (whether from government, local extension agents, or non-government organizations) towards small successful real-time case studies. For example, technology showcases of small-scale bioenergy projects with a focus on local and regional benefits such as employment and agricultural diversification could be an effective strategy for improving communication. The focus of the messages could be on the local and rural development. The past studies have shown that biomass 
energy production is an ideal candidate for decentralized production at the local and rural level [43] and thus, can fit well with the opinion of the general public if the production takes into consideration the local community opinion and participation.

\section{Study limitations}

There were some inherent constraints of our data collection that suggest caution in interpretation of some findings and also pave the path to future research. While the results provide a useful review of how citizens in the two states (NC and TN) those are of economic and political relevance to the SE region form opinions about bioenergy, it is important to note that these findings may not be applicable to all states in the Southeast US. This is especially important to note given some small differences in perceptions of bioenergy between the two states, especially with regard to awareness of feedstocks. A second limitation is the use of weighting parameters to infer the data to the overall states. Although weights have been used successfully to make inferences to a larger population in various studies, including the Census Bureau, there are situations in which weight estimations can reduce the overall precision of the data $[45,38]$. When very large or very small weights are obtained for some observations, the corresponding variance of the estimates increase, and thus, cautionary measures should be used in interpreting the data. To correct for the precision, we used smaller binned categories to constrain the inflation of the weighting estimates using the raking procedure.

While this study has identified some key attitudes and opinion dynamics around bioenergy and biofuels, future research could expand the study to examine a number of additional issues to arrive at a more comprehensive understanding of attitude formation around bioenergy. As indicated earlier, given varying responses from consumers, we believe that a segmentation of consumers or the general public [31] will be helpful in garnering a deeper understanding of how different the risk and opportunity perceptions are for each unique segment in the general population.

It is important to explore the complex dynamics between various stakeholder groups. Bioenergy can have a significant impact on consumers, farmers, forest landowners, industry, NGOs, local communities, and the general public, and each of these stakeholder groups may have varying and at times, opposing views. Thus, collecting data on the other stakeholders about similar themes (as shown by the principal component analysis) will improve the overall understanding of different facets of the informed and uninformed population about bioenergy.

\section{Competing interests}

The authors declare that they have no competing interests.

\section{Authors' contributions}

RR designed the study, conducted the survey, and analyzed and interpreted the results. SD participated in designing the study and further developed the analyses-PCA part-and the interpretation. SK directed the efforts improving the questionnaire - filled the questionnaire and distributed it, the study design, and participated in the interpretation. Developing the paper was a collaborative work of all authors. All of the authors approved this manuscript.

\section{Authors' information}

SK is a professor of Forest Biomaterials at NC State University. His research includes the sustainable production of energy and materials from biomass and the application of novel analytical tools to biomass. Before joining NCSU, he spent 13 years at the DOE's National Renewable Energy Laboratory (NREL) working on biomass conversion technologies. Prior joining NREL, he worked in the industry for 7 years developing new cellulose-based materials and membrane processes.

SD is an associate professor in the Wood Products business area specializing in strategic marketing, distribution and value addition strategies, and marketing research methods. SD received her Ph.D. in Wood Products Marketing from The Pennsylvania State University and her Master's degree in Forest Management from the Indian Institute of Forest Management. Recent research has focused on managing and creating customer value in the forest products industry, product differentiation, and competitive positioning and product distribution strategies.

RR is a postdoctoral scholar of Forest Biomaterials at NC State University, specialized in sustainability of the biomass supply chain. He pursued an M.S. in Forestry Engineering, an M.S. in Environmental Engineering from the University of West Hungary, an M.S. in Economics from Budapest Business School, and a Ph.D. in Forest Biomaterials from NCSU. Previously, he spent 17 years as a health, safety, and environmental protection leader in the petrochemical industry.

\section{Acknowledgements}

The authors thank to the respondents and the IBSS project for providing funding for this study. The IBSS project is supported by Agriculture and Food Research Initiative Competitive Grant no. 2011-68005-30410 from the USDA National Institute of Food and Agriculture.

Received: 24 January 2016 Accepted: 2 June 2016 Published online: 22 June 2016

\section{References}

1. U.S. Department of Energy (2011) Billion Ton update: biomass supply for a bioenergy and bioproducts industry. https://www1.eere.energy.gov/ bioenergy/pdfs/billion_ton_update.pdf Accessed 2 Oct 2015.

2. Halder P, Pietarinen J, Havu-nuutinen S et al (2016) The theory of planned behavior model and students' intentions to use bioenergy: a cross-cultural perspective. Renew Energy 89:627-635

3. Halder P, Pietarinen J, Havu-Nuutinen S et al (2013) Knowledge, perceptions, and attitudes as determinants of youths' intentions to use bioenergy-a cross-national perspective. Int J Green Energy 10:797-813

4. Zarnikau J (2003) Consumer demand for "green power" and energy efficiency. Energy Policy 31:1661-1672

5. Upreti BR, van der Horst D (2004) National renewable energy policy and local opposition in the UK: the failed development of a biomass electricity plant. Biomass Bioenergy 26:61-69

6. Upham P, Shackley S, Waterman H (2007) Public and stakeholder perceptions of 2030 bioenergy scenarios for the Yorkshire and Humber region. Energy Policy 35:4403-4412

7. Wegener DT, Kelly JR (2008) Social psychological dimensions of bioenergy development and public acceptance. BioEnergy Res 1:107-117

8. Popp M, Van de Velde L, Vickery G et al (2009) Determinants of consumer interest in fuel economy: lessons for strengthening the conservation argument. Biomass Bioenergy 33:768-778

9. Scarpa R, Willis K (2010) Willingness-to-pay for renewable energy: primary and discretionary choice of British households' for micro-generation technologies. Energy Econ 32:129-136 
10. Savvanidou E, Zervas E, Tsagarakis KP (2010) Public acceptance of biofuels. Energy Policy 38:3482-3488

11. West J, Bailey I, Winter M (2010) Renewable energy policy and public perceptions of renewable energy: a cultural theory approach. Energy Policy 38:5739-5748

12. Zografakis N, Sifaki E, Pagalou M et al (2010) Assessment of public acceptance and willingness to pay for renewable energy sources in Crete. Renew Sustain Energy Rev 14:1088-1095

13. Qu M, Ahponen P, Tahvanainen L et al (2011) Chinese university students' knowledge and attitudes regarding forest bio-energy. Renew Sustain Energy Rev 15:3649-3657

14. Zhang Y, Yu Y, Li T, Zou B (2011) Analyzing Chinese consumers' perception for biofuels implementation: the private vehicles owner's investigating in Nanjing. Renew Sustain Energy Rev 15:2299-2309

15. Cacciatore MA, Binder AR, Scheufele DA, Shaw BR (2012) Public attitudes towards biofuels. Politics and the Life Sciences 31:36-51.

16. Halder P, Arevalo J, Mola-yudego B, Gritten D (2015). Energy Security and Development 377-391.

17. Selfa T, Kulcsar L, Bain C et al (2011) Biofuels bonanza? Exploring community perceptions of the promises and perils of biofuels production. Biomass Bioenergy 35:1379-1389

18. Dwivedi P, Alavalapati JRR (2009) Stakeholders' perceptions on forest biomass-based bioenergy development in the southern US. Energy Policy 37:1999-2007

19. Radics IR, Dasmohapatra S, Kelley SS (2015) Systematic review of bioenergy perception studies. BioResources 10:8770-8794.

20. Aguilar FX, Cai Z (2010) Exploratory analysis of prospects for renewable energy private investment in the U.S. Energy Econ 32:1245-1252

21. Delshad AB, Raymond L, Sawicki V, Wegener DT (2010) Public attitudes toward political and technological options for biofuels. Energy Policy 38: 3414-3425

22. Petrolia DR, Bhattacharjee S, Hudson D, Herndon CW (2010) Do Americans want ethanol? A comparative contingent-valuation study of willingness to pay for E-10 and E-85. Energy Econ 32:121-128

23. Plate RR, Monroe MC, Oxarart A (2010) Public perceptions of using woody biomass as a renewable energy source. Journal of Extension 48:3.

24. Binder AR, Cacciatore MA, Scheufele DA et al (2012) Measuring risk/benefit perceptions of emerging technologies and their potential impact on communication of public opinion toward science. Public Underst Sci 21 830-847

25. Mariasiu F (2012) Consumers' attitudes related to biofuel use in transportation. Int Rev Manag Mark 3:1-9

26. Pires, Tyler S (2010) Social perceptions of the biofuel industry in the Southeastern US. Thesis, North Carolina State University, Raleigh, NC, US

27. Nyrud AQ, Roos A, Sande JB (2008) Residential bioenergy heating: a study of consumer perceptions of improved woodstoves. Energy Policy 36:3169-3176

28. Hartmann P, Apaolaza-lbáñez V (2012) Consumer attitude and purchase intention toward green energy brands: the roles of psychological benefits and environmental concern. J Bus Res 65:1254-1263

29. Skipper D (2007) Consumer attitudes regarding biofuels. Thesis, University of Arkansas, Fayetteville, AR, US

30. Borchers AM, Duke JM, Parsons GR (2007) Does willingness to pay for green energy differ by source? Energy Policy 35:3327-3334

31. Van de Velde L, Verbeke W, Popp M et al (2009) Perceived importance of fuel characteristics and its match with consumer beliefs about biofuels in Belgium. Energy Policy 37:3183-3193

32. Halder P, Pietarinen J, Havu-Nuutinen S, Pelkonen P (2010) Young citizens' knowledge and perceptions of bioenergy and future policy implications. Energy Policy 38:3058-3066

33. Halder P, Prokop P, Chang C-Y et al (2011) International survey on bioenergy knowledge, perceptions, and attitudes among young citizens. BioEnergy Res 5:247-261

34. Raza G, Singh S (2011) Public understanding of environment and bioenergy. Journal of Science Communication 10:1824-2049.

35. Dillman DA, Smyth JD, Christian LM (2009) The tailored design method, 4th edn. Wiley, Hoboken

36. Battaglia M, Hoaglin D, \& Frankel M (2012). Practical considerations in raking survey data. Survey Practice 2(5)

37. Gelman A (2007) Struggles with survey weighting and regression modeling Stat Sci 22:153-164
38. Shlens J (2014) A tutorial on principal component analysis. arXiv Prepr. arXiv1404.1100, Mountain View, CA, US

39. George D, Mallery P (2003) SPSS for Windows step by step: answers to selected exercises. http://wps.ablongman.com/wps/media/objects/385/ 394732/george4answers.pdf Accessed 2 Oct 2015

40. Van de Velde L, Verbeke W, Popp M, Van Huylenbroeck G (2010) Trust and perception related to information about biofuels in Belgium. Public Understanding of Science 20(5):595-608

41. Resch G, Held A, Faber T et al (2008) Potentials and prospects for renewable energies at global scale. Energy Policy 36:4048-4056

42. Abt RC, Abt KL, Cubbage FW, Henderson JD (2010) Effect of policy-based bioenergy demand on southern timber markets: a case study of North Carolina. Biomass Bioenergy 34:1679-1686

43. Gerber N (2008) Bioenergy and rural development in developing countries: a review of existing studies. Discuss. Pap. http://ageconsearch.umn.edu/ bitstream/37862/2/ZEF\%20DP\%20122.pdf Accessed 2 Oct 2015.

44. Rohracher H, Bogner T, Späth P, Faber F (2003) Improving the public perception of bioenergy in the EU. Report. https://www.researchgate.net/ publication/255626229_Improving_the_public_perception_of_bioenergy_ in_the_EU Accessed 2 Oct 2015

\section{Submit your manuscript to a SpringerOpen ${ }^{\circ}$ journal and benefit from:}

- Convenient online submission

- Rigorous peer review

- Immediate publication on acceptance

- Open access: articles freely available online

- High visibility within the field

- Retaining the copyright to your article

Submit your next manuscript at $>$ springeropen.com 